\title{
Predictors of Students' Knowledge in General Physics
}

\author{
Marisol Solis-Foronda \\ College of Education, Isabela State University, Cauayan City, Isabela, Philippines
}

Received May 13, 2020; Revised June 17, 2020; Accepted July 20, 2020

Copyright $\odot 2020$ by authors, all rights reserved. Authors agree that this article remains permanently open access under the terms of the Creative Commons Attribution License 4.0 International License

\begin{abstract}
The role of physics as a branch of science in the development of society is highly recognized. However, the decline in the students' performance in physics becomes a hindrance in achieving the primary goal of physics. Thus, it is imperative to determine the factors that could possibly affect the physics performance of students in the classroom. A total of 128 students from the programs Bachelor of Secondary Education and Bachelor of Elementary Education were randomly selected to participate in this study. Moreover, the cross-sectional-predictive non-experimental quantitative research design served as the framework to determine the predictors of students' performance in Physics. Furthermore, the data such as attitude, creativity skills, and knowledge were gathered using questionnaires and analyzed using multiple regression. With this, the study found out that the creativity skills and attitude of the students in General Physics do not predict the students' level of knowledge in General Physics. This study implies that students who are more creative do not necessarily have a high level of knowledge in General Physics. Similarly, students who have a positive attitude towards the subject do not certainly lead to an increased level of knowledge in General Physics. Thus, the students' level of knowledge in General Physics depends on their ability to process and store information.
\end{abstract}

Keywords Creativity Skills, Attitude, Knowledge, General Physics

\section{Introduction}

The role of physics is recognized in the society for over an extended period, but despite the fact that it made a significant contribution to today's society, there is a decline in enrolment and performance over the years [1]. The decline in enrolment and performance could be attributed to the perception of the students from secondary school to university that Physics as a difficult subject [2]. The primary goal of physics is to discover and verify the law which governs a specific phenomenon derived from theory. The demonstration of the experiment is essential for understanding the principles of physics. Performing tests by one's hand are far more important because it involves learning by doing. Practical work brings the basis of behavior changes in students such as scientific temperament, curiosity, interest, and creativity.

The students play a vital role in their systematic and scientific training as what educational psychologists said. However, many students considered physics as one of the most prevailing and problematic subjects in the realm of science. They perceived physics as a problematic subject during high school days and become more evasive when they reach college [3].

Studies showed that knowledge and attitude play an important role in learning. To facilitate learning, one of the fundamental principles that instructors employ is understanding students' knowledge. And it is well known that students build on what they already know and have come to realize through formal and informal experiences. People develop attitudes and beliefs as they progress through life. A knowledge-management model incorporating e-learning and product creation as well as the scaffolding of a teacher can promote the creativity of the learners [4]. It is also said that knowledge, attitudes, and beliefs evaluation is important for students in the early semester since students' knowledge may either promote or hinder their learning $[5,4]$. Thus, this study described the creativity, knowledge and attitude of students towards physics and explained the relationship of these variables specifically in general physics subjects.

In education, many studies have concluded that the academic success of students depends on their attitude towards a subject $[6,7]$. Moreover, students who have a positive attitude to science can lead to a positive commitment to science which leads to a lifelong interest and learning in science [8]. Therefore, development or formation of a positive attitude in one's life is helpful facing any challenge. Attitudes are beliefs and emotions which comprise the affective domain of learners. While the 
positive attitude helps in a better comprehension of the nature of learning for the learners, it also makes the students more open to learning, increases their expectations from the learning process and reduces their anxiety levels. In the study of Weingurgh cited by Craker, almost fifty percent of the students at the primary schools may lose interest due to negative attitudes towards the subject [9]. Contrary, the study of Sitotaw and Tadele established that students have positive attitudes towards physics-related subjects [10].

Similarly, the importance of creativity cannot be discounted in the field of science. Creativity is being used by scientists in doing scientific research in every stage [11]. With this, students who can think creatively in doing scientific work can also apply this skill in other fields [12]. Moreover, creativity is considered a good predictor of academic achievement among students [13]. The majority of the studies deal with the knowledge, creativity skills and attitude of the students in physics as different and separate variables. Some studies focused only on the attitude of the students and its effect on their achievement, others just determined the level of creativity skills of the students and its effect on their learning. The research questions are as follows:

1. What is the level of creativity skills of the students?

2. What is the attitude of the respondents when dealing with the subject of general physics?

3. What is the level of students' knowledge in general physics?

4. What are the predictors of students' knowledge in general physics?

\section{Methods}

\subsection{Research Design}

Considering the goal of this study, to determine the predictors of students' knowledge about general physics, the cross-sectional-predictive non-experimental quantitative by Burke Johnson was used as the research framework. The cross-sectional design is the most appropriate because the data were gathered across the population in the most recent time and did not involve data from the past. On the other hand, the predictive aspect of the design served as the basis of determining the predictors of students' knowledge in general physics.

\subsection{Sample and Sampling Technique}

The respondents of the study were the students from the College of Teacher Education who just recently finished general physics subjects during the previous semesters. The minimum sample size was computed using the rule of thumb for multiple regression by Tabachnick and Fidell (1996). The sample size was composed of one hundred twenty-eight (128) Bachelor of Secondary Education (BSE) and Bachelor of Elementary Education (BEED) students of the second semester of the school year 2018-2019. 128 samples had met the minimum number of samples required for the use of AMOS software. The BSE students included the third-year college students which comprised of 18 males and 12 females. Also, there were 13 males and 17 females fourth-year BSE students included in this study. Similarly, the third-year BEED college students were composed of 6 males and 27 females, while the fourth-year BEED college students included 7 males and 29 females. The respondents were randomly selected from the class using a fishbowl technique.

\subsection{Data Collection}

In collecting the data, a request letter was addressed to the registrar to get a copy of the enrolled students in general physics for the previous semester. Upon receiving the copy of students who have enrolled in general physics, the researcher started to float the questionnaires to the randomly selected respondents. A consent letter was also given to the respondents requesting them to participate in answering the questionnaires. The test for assessing their level of knowledge in general physics was administered during their vacant time and collected right after the 30 -minute time allotment for answering the twenty (20) multiple choice test questions. The researcher collected the respondents' attitude and creativity skills by giving them the questionnaires successively to that of the knowledge assessment tool.

\subsection{Data Gathering Instruments}

The instrument used in gathering the data for students' knowledge is a questionnaire adapted from Praxis (The Praxis Study Companion). The Physics Content Knowledge Test is designed to measure the knowledge and competencies necessary for beginning teachers. The test questions evaluate the content areas that focus on conceptual understanding, critical thinking, and problem solving in Physics. The test items were developed and reviewed in collaboration with practicing high school Physics teachers, teacher-educators, and higher education content specialists to keep the test updated and representative of current standards.

In measuring the attitude of the respondents, a questionnaire from Bambry et al. (2005) was adopted. The questionnaire consisted of 20 items in total wherein the 12 items are about the students' attitude towards physics lessons and 8 items are about the students' attitude towards physics. While, the creativity instrument was developed by the researcher. To ensure the reliability of the creativity instrument a pilot study of the questionnaire was made on 25 students and the reliability of the questionnaire was checked at this stage. The reliability factor of the applied 
scale regarding the sampling area came out to be at Cronbach's Alpha $=0.73$.

\subsection{Data Analysis}

The data collected in this study were analyzed using the software SPSS and AMOS. The knowledge scores of the respondents towards physics were analyzed and explained using mean and standard deviation. While, the collected data for attitude were scaled into Strongly Agree, Agree, Neutral, Disagree and Strongly Disagree with value points of 5, 4, 3, 2 and 1 respectively. The negative responses of the students were coded in reverse pattern to show their negative attitudes. On the other hand, the level of creativity skills of the respondents was scaled as 1-never, 2-rarely, 3-sometimes, 4-usually, and 5-always. Finally, to determine the predictors of students' knowledge in General Physics and the mediating effect of creativity, the software AMOS was used.

\section{Results}

The results of this study are shown in Table 1, Figure 1, and Table 2. Table 1 shows the descriptive parameters of the students' creativity skills, attitude towards General Physics, and Knowledge in General Physics. As seen in the table, the students described their general creative skills (communication, collaboration, open-mindedness, and flexibility) as "sometimes" $(\mathrm{X}=3.00 ; \mathrm{SD}=.539)$. The description "sometimes" pertains to the execution or practice of creative activities relating to communication, collaboration, open-mindedness, and flexibility as mentioned in the P21 Skills Framework. Contrary, the attitude of the students towards General Physics is positive due to the presence of laboratory experiments $(X=3.29$; $\mathrm{SD}=.366)$. However, the knowledge of the students of basic and general concepts in physics is unsatisfactory ( $\mathrm{X}=$ 5.39; $\mathrm{SD}=1.94)$. The students have a very low understanding of conceptual and procedural knowledge. Figure 1 and Table 2 show that there is no relationship between creativity and knowledge as well as attitude and knowledge. With this, the regression model proved that creativity skills $(\beta=.526 ; p=.111>0.05)$ and attitude towards general physics $(\beta=-.244 ; \mathrm{p}=.614>0.05)$ do not predict the students' knowledge of general physics.

Table 1. Description of students' level of creativity skills, attitude towards general physics and knowledge in general physics.

\begin{tabular}{|c|c|c|c|}
\hline Variables & Mean & $\begin{array}{c}\text { Standard } \\
\text { deviation }\end{array}$ & $\begin{array}{c}\text { Descriptive } \\
\text { Interpretation }\end{array}$ \\
\hline $\begin{array}{c}\text { Creativity } \\
\text { Skills }\end{array}$ & 3.00 & .539 & Sometimes \\
\hline Attitude & 3.29 & .366 & Positive \\
\hline Knowledge & 5.39 & 1.94 & Unsatisfactory \\
\hline
\end{tabular}

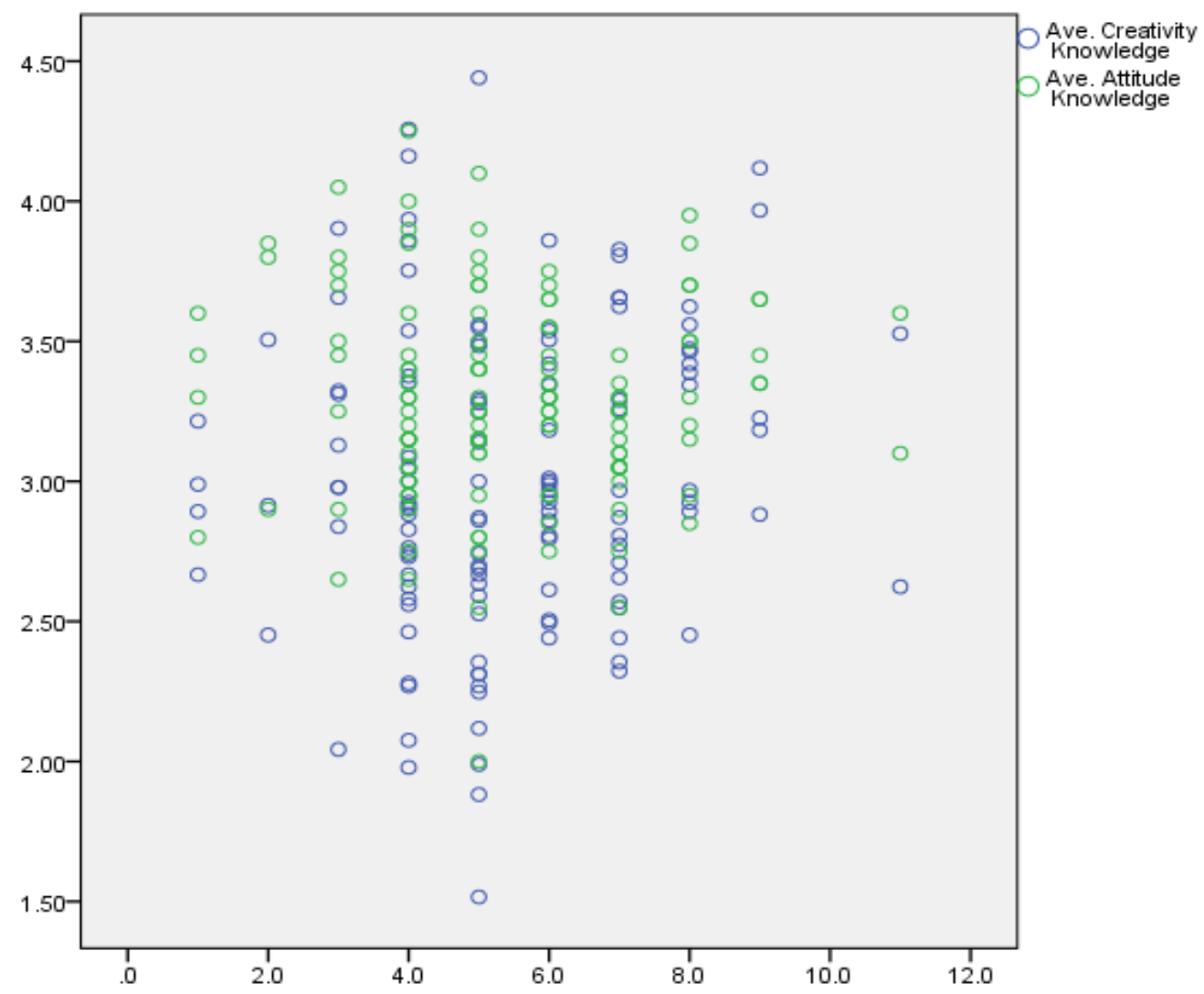

Figure 1. Scatter Plot showing no relationship between the independent variables and dependent variable 
Table 2. Predictors of students' knowledge of general physics

\begin{tabular}{|c|c|c|c|c|c|}
\hline \multirow{2}{*}{ Model } & \multicolumn{2}{|c|}{$\begin{array}{l}\text { Unstandardized } \\
\text { Coefficients }\end{array}$} & $\begin{array}{c}\text { Standardized } \\
\text { Coefficients }\end{array}$ & \multirow[t]{2}{*}{$\mathrm{T}$} & \multirow[t]{2}{*}{ Sig. } \\
\hline & B & Std. Error & Beta & & \\
\hline Constant & 4.618 & 1.672 & & 2.763 & .007 \\
\hline Creativity & .526 & .327 & .146 & 1.606 & .111 \\
\hline Attitude & -.244 & .482 & -.046 & -.506 & .614 \\
\hline
\end{tabular}

Dependent Variable: Knowledge of General Physics

\section{Discussion}

The creativity skill parameters in this study include aspects such as communication, collaboration, open-mindedness, and flexibility. The findings in Table 1 showed that the students sometimes demonstrate or practice activities that display their creative skills. The areas included in the creativity skill questionnaire are mentioned in the Creating Thinking: An Essential Skill for the 21st Century (2016) which includes activities related to communicating, collaborating, being open-minded, and being flexible while they were studying General Physics. Some of the activities mentioned in the questionnaire area include: playing music in public, acting in a play, debating and arguing, helping other people, teaching someone how to do something, comparing different points of view and others. Considering the level of creativity skills of the students, it can be said that their creativity skills in terms of the four parameters mentioned were not fully exercised or practiced. The creativity skills of the students should be developed more to adapt to the changing landscape of the 21st century education. The Partnership 21st Century Skills Framework identified creativity skills as one of the life skills essential for the students to become competitive in the workforce [14]. Contrary, the students in this study showed a positive attitude towards the learning of General Physics. The students particularly attributed their positive attitude to activities such as Physics lessons are exciting, physics experiments are exciting, physics experiments are useful and others. Erylmaz and Yildiz also reported and supported this result in their study [15]. Contrary to the positive attitude of the students towards the subject, the students' level of knowledge in General Physics is unsatisfactory. The students' knowledge of basic concepts in General Physics is very low considering that the mean score did not even reach half of the total item. The students' knowledge or understanding of the basic concept, critical thinking, and problem solving in physics is very low. The result in Table 2 supported by Figure 1 means that students who display a more creative skill and show a positive attitude towards Physics do not necessarily lead to an increase or a high knowledge in Physics. The findings of this study imply that the state of mind does not necessarily help a person acquire knowledge [16], it could be the psychology of the environment which a student lives. Moreover, the students acquire knowledge through the interaction of two factors. (1) The ability to process and store information, and (2) the number and frequency of academically oriented experiences, called the fluid intelligence as explained by Cattell cited by Kvist, \& Gustafsson, [17]. The result only proves that creativity and attitude are not predictors of knowledge in General Physics. However, knowledge can be developed through different methods and techniques; thus, the students acquire knowledge through the interaction of their ability to process and store information as well as the frequency of academically oriented experiences.

\section{Conclusion}

The study concluded that creativity skills and attitude towards physics do not predict or influence the level of students' knowledge of Physics. Hence, a positive or negative attitude towards physics does not predict the increase and decrease of students' level of knowledge. Similarly, students who demonstrate a more creative skill do not necessarily result in better knowledge in Physics. The students' ability to acquire knowledge in Physics depends on their skill to process and store information. However, further studies focusing on the effective method to improve the students' knowledge in general physics are recommended.

\section{REFERENCES}

[1] KNEC (2004, 2011). KCSE examination \& performance report. Nairobi.

[2] Erdemir N, (2009). Determining students' attitude towards physics through problem-solving strategy, Asia-Pacific Forum on Science Learning and Teaching, 10 (2).

[3] Rivard, L. P., \& Straw, S. B. (2000). The effect of talk and writing on learning science: An exploratory study. Science education, 84(5), 566-593.

[4] Yeh, Y. C., Yeh, Y. L., \& Chen, Y. H. (2012). From knowledge sharing to knowledge creation: A blended knowledge-management model for improving university students' creativity. Thinking Skills and Creativity, 7(3), 245-257.

[5] Gee, J. (2012). Importance of prior knowledge to learning. Illinois State University Retrieved from https://news.illinoisstate.edu/2012/01/importance-of-prior-k nowledge-to-learning/

[6] Verešová, M., \& Malá, D. (2016). Attitude toward school and learning and academic achievement of adolescents. In 7th International Conference on Education and Educational Psychology, Published by Future Academy.

[7] Geddes, J. D., Murrell, A. R., \& Bauguss, J. (2010). Childhood Learning: An Examination of Ability and Attitudes toward School. Creative Education, 1(3), 170-183. 
[8] Simpson R, \& Oliver J (1990). A summary of major influences on attitude towards and achievements in science among adolescent students. Science Education, 74, 1-18.

[9] Craker DE (2006). Attitudes toward Science of Students Enrolled in Introductory Level Science Courses at UW-La Crosse, UW-L Journal of Undergraduate, IX.

[10] Sitotaw, B. \& Tadele, K. (2016). Students’ attitudes towards physics in primary and secondary schools of Dire Dawa City administration, Ethiopia. World Journal of Educational Research and Reviews, 3(1): 044-050.

[11] Abd-el Khalick, F. \& Lederman, N.G. (2000). The influence of history of science courses on students' views of nature of science. Journal of Research in Science Teaching, 37 (10), 1057-1095.

[12] Meador, K. (2003). Thinking creatively about science suggestions for primary teachers. Gifted Child Today, 26(1), 25-29.

[13] Olatoye, R., Akintude S., \& Yakasi, M. (2010). Creativity, emotional intelligence and academic achievement of
Business Administration Students. Electronics journal of Research in Educational psychology, 8(2), 763-786

[14] Partnership for 21st Century Skills. (2006). A state leader's action guide to 21st century skills. A new vision for education: Executive summary. Tucson, AZ: Partnership for 21st Century Skills.

[15] Eryilmaz, A., Yildiz, İ., \& Sedef, A. K. I. N. (2010). Investigating of relationships between attitudes towards physics laboratories, motivation and amotivation for the class engagement. Eurasian Journal of Physics and Chemistry Education, 1(1), 59-64.

[16] Leahey, T. H. (2000). Control: A history of behavioral psychology. The Journal of American History, 87(2), 686-687.

[17] Kvist, Ann \& Gustafsson, Jan-Eric. (2008). The relation between fluid intelligence and the general factor as a function of cultural background: A test of Cattell's Investment theory. Intelligence. 36. 422-436. 10.1016/j.intell.2007.08.004. 